Rodwell, A. W. (1953). J. gen. Microbiol. 8, 224-232.

\title{
The Occurrence and Distribution of Amino-acid Decarboxylases within the Genus Lactobacillus
}

\author{
By A. W. RODWELL* \\ Medical Research Council Unit for Chemical Microbiology, \\ Biochemical Laboratory, Cambridge
}

SUMMARY: Bacteria possessing active amino-acid decarboxylases, isolated from horse-stomach and sheep-rumen contents, were classified within the genus Lactobacillus. One strain, studied in detail, was a homolactic fermenter, the lactic acid formed being optically inactive; lactose was not fermented. Of twenty-six named strains belonging to eight species of the genus, only two possessed amino-acid decarboxylases, namely, one strain of $L$. pentoaceticus and one strain of $L$. bifidus.

The occurrence and distribution of amino-acid decarboxylases among strains of bacteria belonging to many species have been the subject of extensive studies by Gale $(1940 a, b, 1941)$, but strains of the genus Lactobacillus were not included. With the exception of two strains of $L$. arabinosus examined by Eggerth (1939) which did not produce histamine under the conditions of cultivation used, lactobacilli have not been examined for amine production by earlier workers. Of thirty-nine strains of lactobacilli isolated from the human mouth which were examined by Lagerborg \& Clapper (1952), a number were shown to possess amino-acid decarboxylases. Two named strains examined, a strain of $L$. casei and one of $L$. arabinosus, showed no decarboxylase activity. The present paper records the examination of strains of Lactobacillus spp. isolated from horse stomach and sheep rumen and twenty-six named strains, for amino-acid decarboxylases.

\section{MATERIALS AND METHODS}

\section{Growth media}

Wheat-mash medium. Wheat-mash medium was prepared by adding $15 \mathrm{ml}$. of $10 \%(\mathrm{w} / \mathrm{v})$ pepsin solution, sterilized by Seitz filtration, to $5 \mathrm{~g}$. sterile ground wheat (autoclaved at $25 \mathrm{lb}$./sq.in. for $1 \mathrm{hr}$.). The $\mathrm{pH}$ value of the mash was then adjusted to 3.5-4.0 by the aseptic addition of hydrochloric acid.

Wheat-digest histidine broth. One l. distilled water and $100 \mathrm{ml}$. of $10 \%(\mathrm{w} / \mathrm{v})$ pepsin solution were added to $200 \mathrm{~g}$. ground wheat, the $\mathrm{pH}$ value adjusted to 3.0 and the mixture incubated at $37^{\circ}$ for 4-5 days under toluene, with occasional shaking. The supernatant liquid was collected by decantation and centrifugation, heated to $100^{\circ}$, filtered, and to the filtrate $1 \%(\mathrm{w} / \mathrm{v})$ Bactopeptone (Difco), $1 \%(\mathrm{w} / \mathrm{v})$ glucose and $0.1 \%(\mathrm{w} / \mathrm{v})$ L-histidine hydrochloride were added. The $\mathrm{pH}$ value was adjusted to 6.0 and the medium autoclaved at $10 \mathrm{lb} . / \mathrm{sq}$.in. for $20 \mathrm{~min}$. For solid media, $3 \%(\mathrm{w} / \mathrm{v})$ Bacto-agar was added before autoclaving.

* Present address: Commonwealth Scientific and Industrial Research Organization, Animal Health Research Laboratory, Parkville, Melbourne, N.2, Australia. 
Casein liver-digest medium. This contained: casein digest (pancreatic, equivalent to $10 \%(\mathrm{w} / \mathrm{v})$ casein), $200 \mathrm{ml}$; horse-liver digest (pancreatic, equivalent to $10 \%(\mathrm{w} / \mathrm{v})$ liver), $50 \mathrm{ml}$.; $\mathrm{CH}_{3} \mathrm{COONa} .3 \mathrm{H}_{2} \mathrm{O}, 10 \mathrm{~g}$.; $\left(\mathrm{NH}_{4}\right)_{2} \mathrm{SO}_{4}$, $3 \mathrm{~g}$.; $\mathrm{MgSO}_{4} .7 \mathrm{H}_{2} \mathrm{O}, 0.2 \mathrm{~g}$; $\mathrm{FeSO}_{4} .7 \mathrm{H}_{2} \mathrm{O}, 0.01 \mathrm{~g}$; $\mathrm{MnSO}_{4} .4 \mathrm{H}_{2} \mathrm{O}, 0.01 \mathrm{~g}$; $\mathrm{KH}_{2} \mathrm{PO}_{4}, 1$ g.; $\mathrm{K}_{2} \mathrm{HPO}_{4}, 1$ g.; water to $900 \mathrm{ml}$. The $\mathrm{pH}$ value was adjusted to 6.5 and the medium sterilized by autoclaving at $15 \mathrm{lb} . / \mathrm{sq}$.in. for $15 \mathrm{~min}$. Glucose $(20 \mathrm{~g} . / 100 \mathrm{ml}$. medium) sterilized separately was added after autoclaving. For solid medium, $3 \%(w / v)$ agar and the glucose were added before autoclaving.

Complete, semi-defined medium. The medium used to test the growth factor requirements of the strains had the following composition/10 ml. medium : $\mathrm{CH}_{3} \mathrm{COONa} .3 \mathrm{H}_{2} \mathrm{O}, 100 \mathrm{mg}$. ; $\left(\mathrm{NH}_{4}\right)_{2} \mathrm{SO}_{4}, 30 \mathrm{mg}$.; $\mathrm{MgSO}_{4} \cdot 7 \mathrm{H}_{2} \mathrm{O}, 2 \mathrm{mg}$; ; $\mathrm{FeSO}_{4} .7 \mathrm{H}_{2} \mathrm{O}, 0 \cdot 1 \mathrm{mg}$.; $\mathrm{MnSO}_{4} .4 \mathrm{H}_{2} \mathrm{O}, 0 \cdot 1 \mathrm{mg}$.; $\mathrm{NaCl}, 0.1 \mathrm{mg}$.; $\mathrm{KH}_{2} \mathrm{PO}_{4}, 10 \mathrm{mg}$.; $\mathrm{K}_{2} \mathrm{HPO}_{4}$, $10 \mathrm{mg}$. ; glucose, $100 \mathrm{mg}$. ; casein hydrolysate, $100 \mathrm{mg}$; L-tryptophan, $1 \mathrm{mg}$; L-cystine, $1 \mathrm{mg}$.; L-glutamine, $1 \mathrm{mg}$.; L-asparagine, $1 \mathrm{mg}$.; thiamine hydrochloride, $1 \mu \mathrm{g}$.; pyridoxin hydrochloride, $3 \mu \mathrm{g}$.; calcium pantothenate, $1 \mu \mathrm{g}$.; riboflavin, $1 \mu \mathrm{g}$.; nicotinamide, $1 \mu \mathrm{g}$.; biotin, $2 \mathrm{~m} \mu \mathrm{g}$.; $p$-aminobenzoic acid, $3 \mu \mathrm{g}$.; pteroylglutamic acid, $0 \cdot 1 \mu \mathrm{g}$.; adenine sulphate, $100 \mu \mathrm{g}$.; guanine sulphate, $100 \mu \mathrm{g}$.; uracil, $100 \mu \mathrm{g}$.; xanthine, $100 \mu \mathrm{g}$.; Bactopeptone (charcoaltreated), $3 \mathrm{mg}$.; Tween 80, 0.001 ml.; choline chloride, $25 \mu \mathrm{g}$.; inositol, $25 \mu \mathrm{g}$. The $\mathrm{pH}$ value was adjusted to 6.5 before autoclaving for $10 \mathrm{~min}$. at $10 \mathrm{lb}$./sq.in.

Semi-defined medium. This medium, used for the cultivation of strain $30 a$, had the same composition as the complete semi-defined medium but with the omission of $p$-aminobenzoic acid, guanine sulphate, xanthine, L-glutamine, choline chloride and inositol. In some experiments Bactopeptone was replaced by $0.5 \%(v / v)$ vitamin $B_{12}$ concentrate prepared from liver ('Examen', Glaxo Laboratories).

\section{Growth temperatures}

The incubation temperature for cultures of the unclassified strains of lactobacilli was $37^{\circ}$; cultures of the named species of lactobacilli were incubated at their optimal growth temperature as indicated in Table 3.

\section{Identification of histamine in cultures}

Histamine was estimated and identified in cultures of the strains of lactobacilli isolated in Australia by pharmacological assay using the guinea-pig ileum. The neutralized culture supernatants, suitably diluted in RingerTyrode solution, were assayed directly. The specificity of the contractions was checked by the use of drugs (atropine, or the antihistamine drug Neoantergan : $N^{\prime}$-p-methoxybenzyl- $N^{\prime}$-pyridyl- $N, N$-dimethylethylenediamine), or by treating the culture supernatants with preparations having diamineoxidase activity. A paper partition chromatography method was later developed as a qualitative or roughly quantitative method for the identification of histamine in bacterial cultures. Suitable solvent mixtures had the following composition (in parts by volume): (1) $n$-butanol, 100; water, 100; 0.88 sp.gr. ammonium hydroxide, 1 ; (2) ethyl acetate, 100; water, 100; pyridine, 50. Papers were run in the organic phase of the first solvent mixture 
for 4-5 hr., or for 2-3 hr. in the ethyl acetate + pyridine mixture. The papers were then air-dried, and the position of the components giving a positive Pauly diazo reaction determined. The dried papers were sprayed with an aqueous $10 \%(\mathrm{w} / \mathrm{v})$ solution of sodium carbonate, again dried in air, and the mixed diazo reagent applied in parallel lines from a fine pipette. The diazo reagent was prepared as described by Koessler \& Hanke (1919) except that it was used undiluted.

\section{Determination of decarboxylase activity}

The medium used to grow the organisms was casein liver digest medium. The bacterial cells were harvested at the end of the exponential phase of growth, washed once, and resuspended in water. Approximate dry weights of the suspensions were determined by optical density measurement. For the manometric determination of decarboxylase activity the temperature was $30^{\circ}$, oxygen-free nitrogen was used as gas phase and the $\mathrm{pH}$ value of the reaction was controlled with McIlvaine buffer.

\section{ISOLATION AND DESCRIPTION OF STRAINS USED}

Origin and isolation of strains

The unclassified strains used were isolated in Australia during an investigation of the results of gorging with wheat and other cereal grains in horses and ruminants, a condition ascribed by Akerblom (1934) to an enterogenous histaminosis, the histamine being formed by bacterial decarboxylation of histidine in the small intestine. Akerblom implicated an upgrowth of coliform species. In our experiments we found high concentrations of histamine after wheat-feeding, but in contrast to Akerblom's findings, much higher concentrations were present in the stomach than in the small intestine. In several cases we also found histamine in abnormally high concentrations in the rumen of sheep and goats after wheat-feeding.

Histamine was formed in concentrations as high as $1.7 \mathrm{mg} . / \mathrm{ml}$. fluid after incubation of wheat-mash medium inoculated with stomach contents taken from horses fed either on wheat, pasture or hay, or from fasted horses. It was not formed after incubation of uninoculated wheat-mash medium, nor after incubation of mixtures of unsterilized wheat, pepsin and water. The organisms responsible for the formation of histamine in these wheat-mash cultures appeared to be present in the normal microbial flora of the horse stomach.

The microbial flora of the wheat-mash cultures, and also of the stomach of the horse and the rumen of the sheep after wheat-feeding was predominantly Gram-positive, and since coliform species and clostridia were very rare in, or absent from, these materials, it seemed probable that some unrecognized histidine-decarboxylating species were present. Numerous attempts to isolate histidine-decarboxylating organisms by surface culture methods were at first unsuccessful, but success was later obtained with shake cultures. It was subsequently found that the histamine-producing organisms would grow luxuriantly on the surface of suitable solid media in an atmosphere of increased 
carbon dioxide tension; after repeated subcultivation they slowly became able to dispense with added carbon dioxide.

After a preliminary enrichment by subcultivation at low $\mathrm{pH}$ values in wheat-mash medium, which served to suppress growth of many unwanted species, followed either by shake culture in wheat-digest histidine agar (in which the biotype first isolated grows with a characteristic and easily recognizable appearance, Pl. 1, fig. 1), or by surface culture on a suitable solid

\section{Table 1. Production of histamine in wheat-digest histidine broth by strains of bacteria isolated from horse stomach and sheep rumen contents}

Cultures were incubated anaerobically in $\frac{1}{5}$ atmosphere of $\mathrm{CO}_{2}$ for 2 days at $37^{\circ}$. Histamine was estimated by guinea-pig ileum assay.

\begin{tabular}{rlr} 
Strain & \multicolumn{1}{c}{ Source } & $\begin{array}{r}\text { Histamine } \\
(\mu \mathrm{g} . / \mathrm{ml} .)\end{array}$ \\
$6 a$ & Horse stomach (pasture fed) & 30 \\
$6 b$ & Horse stomach (pasture fed) & $\mathrm{Nil}$ \\
$30 a$ & Horse stomach (pasture fed) & 1200 \\
$31 a$ & Horse stomach (pasture fed) & 50 \\
$2 a$ & Horse stomach (after wheat-feeding) & 800 \\
$214 b$ & Sheep rumen (after wheat-feeding) & 60 \\
$214 f$ & Sheep rumen (after wheat-feeding) & $\mathrm{Nil}$
\end{tabular}

medium incubated in $\frac{1}{20}-\frac{1}{5}$ atmosphere carbon dioxide in hydrogen, a number of histidine-decarboxylating strains were isolated from different sources. Colonies were picked from plate or shake cultures into broth medium, e.g. wheat-digest histidine broth or casein liver digest broth supplemented with histidine (1 $\mathrm{mg} . / \mathrm{ml}$.$) , and the formation of histamine in the cultures detected$ either by guinea-pig gut assay, or on paper chromatograms. By these methods active amino-acid decarboxylating strains were isolated in Australia from stomach contents of three horses on pasture diet, from one horse after wheatfeeding, and from the rumen contents of a sheep after wheat-feeding, and at Cambridge from the stomach contents of a pasture-fed horse.

The concentration of histamine produced after 2 days' incubation in wheatdigest histidine broth by some of the strains isolated in Australia is shown in Table 1. Histamine formation by the strains isolated at Cambridge, as shown by the decrease in intensity of the histidine spot and appearance of a spot in the histamine position on paper chromatograms, is shown in Pl. 1, figs. 2 and 3.

\section{Description of strains isolated}

The strains isolated from horse-stomach and sheep-rumen contents have not been identified within the genus Lactobacillus. They have been separated into several biotypes on the basis of morphology, cultural appearance, acids produced during growth, and also on the distribution of amino-acid decarboxylases, since Proom \& Woiwod (1949) consider the production of amines in culture to be of taxonomic importance.

Biotype 1. Strains of $2 a, 30 a, 6 a$ and $31 a$ appeared to be closely related or to belong to the same species. Strain $30 a$ has been used in some studies to be reported later, and was examined in more detail. From growth curves 
relating dry weight of cell material and period of incubation at temperatures of $30,35,40$ and $45^{\circ}$, the optimum growth temperature was judged to be $40^{\circ}$.

Strains $6 a$ and $30 a$ were classed as homolactic fermenting organisms. Approximately $90-95 \%$ of the carbon of glucose which disappeared during growth on glucose-containing media appeared as lactic acid. Only traces of volatile acid (identified as acetic acid) were formed. The lactic acid formed by strain $30 a$ was isolated as the zinc salt and was optically inactive.

Table 2. Nutritional requirements of strains $30 a, 2 a$ and $6 a$

Medium: complete semi-defined medium lacking each constituent singly. - = no effect on growth; $S=$ growth stimulatory; $E=$ essential nutrient.

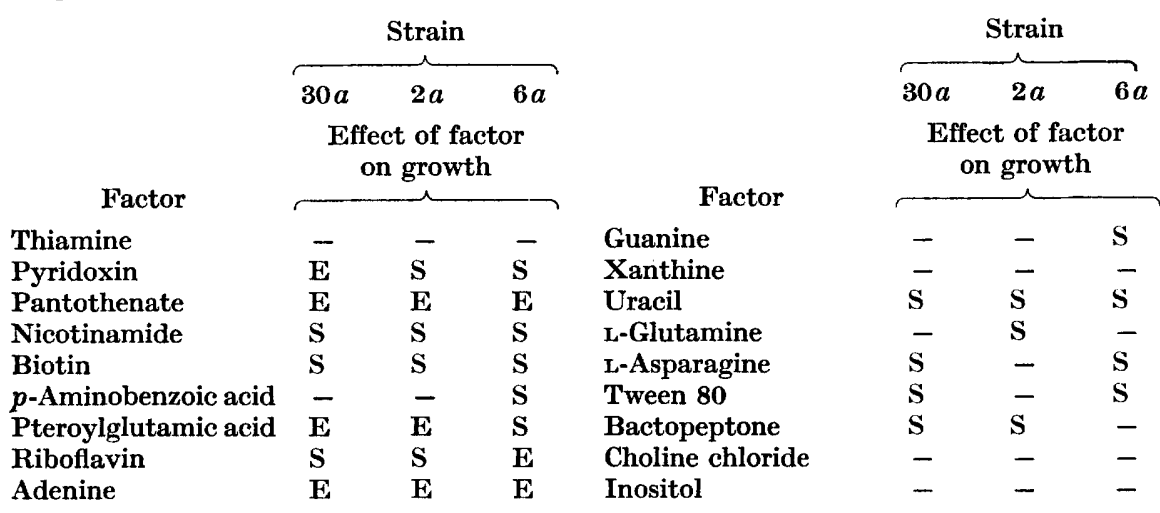

Strains $30 a$ and $6 a$ fermented the same carbohydrates. The carbohydrates fermented by strain $30 a$ were found by its ability to grow in the semi-defined medium to which carbohydrates were added in a concentration of $1 \%(\mathrm{w} / \mathrm{v})$. Of the carbohydrates commonly used in systematic bacteriology, glucose, fructose, mannose, sucrose and trehalose supported growth; the greatest yield of cell material was obtained with sucrose. Qualitatively similar results were obtained with strain $6 a$, for which the amount of growth was judged by titratable acidity.

The nutritional requirements of strains $30 a, 2 a$ and $6 a$ were tested by comparing their growth in the complete semi-defined medium with growth in the medium lacking each of the growth-factor constituents singly. The results are summarized in Table 2 , in which each nutrient is arbitrarily classed as essential, stimulatory or non-essential. The growth-factor requirements of these three strains were essentially similar. The complete, semi-defined medium did not fully satisfy the nutritional requirements of these strains, since increased growth was obtained by addition of crude liver extracts, or of a refined liver extract containing vitamin $B_{12}$ ('Examen'). These could not be replaced by purified vitamin $\mathrm{B}_{12}$.

Finally, strains $30 a$ and $2 a$ decarboxylated the same amino-acids. When first isolated, strains $6 a$ and $31 a$ formed large amounts of histamine in culture, but had lost all decarboxylase activity during the interval between their original isolation and testing by the manometric method. 
Biotype 2. The strains isolated at Cambridge (C1 and C3) resembled the biotype 1 strains in cultural appearance, but differed in the particular aminoacids which were attacked.

Biotype 3. Strains of $6 b$ and $214 f$ were unrelated to any of the strains of biotypes 1 or 2 . They were not homolactic fermenters, and produced gas during growth in fluid media.

Named strains of the genus Lactobacillus. The twenty-six classified strains used to survey the occurrence of amino-acid decarboxylases in named species of the genus are listed in Table 3.

Table 3. Distribution of amino-acid decarboxylases among strains of lactobacilli

\begin{tabular}{|c|c|c|c|c|c|c|}
\hline \multirow{2}{*}{ Strain } & \multicolumn{6}{|c|}{ Decarboxylation of } \\
\hline & Arginine & $\begin{array}{l}\text { Glutamic } \\
\text { acid }\end{array}$ & Histidine & Lysine & Ornithine & Tyrosine \\
\hline $\begin{array}{c}\text { From horse stomach or sheep } \\
\text { rumen. See Table }\end{array}$ & \multicolumn{6}{|c|}{ Values of $Q_{\mathrm{CO}_{2}}$} \\
\hline $30 a$ & - & - & 310 & 14 & 20 & - \\
\hline $2 a$ & - & - & 200 & 21 & 25 & - \\
\hline $6 b$ & 8 & - & - & - & - & - \\
\hline $214 f$ & 6 & - & - & - & - & - \\
\hline C2.1 & 44 & - & 170 & - & - & - \\
\hline C2.3 & 41 & - & 125 & - & - & - \\
\hline $\begin{array}{l}\text { L. pentoaceticus Rudensis } \\
\left(\mathbf{3 0}^{\circ} \text { opt. }\right)\end{array}$ & 26 & - & - & - & - & 6 \\
\hline $\begin{array}{l}\text { L. bifidus; NCTC } 4034 \text { (listed } \\
\text { as L. acidophilaekogenes } \\
\text { Torrey \& Rahe; } 37^{\circ} \text { opt.) }\end{array}$ & 21 & 14 & - & - & - & - \\
\hline
\end{tabular}

Twenty-four other named strains of Lactobacillus did not show decarboxylation of the six amino-acids named in this Table. The twenty-four strains were:

Optimum growth temperature $30^{\circ}$.

L. casei strains: W5, NCTC3253, DCEP, YCT1, A094; L. plantarum strains: 1-4, 1-8, 4125, NCTC3254; L. pentoaceticus strains: 2108; L. pastorianus strains: Pasteur, Shimwell, W4, P.S. Lind, P3.

Optimum growth temperature $37^{\circ}$

L. helveticus strains : NCTC4113, CRC2, CRC3, CRCE1, Booth, Happold; L. acidophilus strain: TC; $L$. delbrueckii strains: NCTC4033, B.

- = no decarboxylation detected.

The strains labelled NCTC are now kept in the National Collection of Industrial Bacteria, Chemical Research Laboratory (Department of Scientific and Industrial Research), Teddington, Middlesex.

\section{Occurrence of amino-acid decarboxylases in lactobacilli}

Washed suspensions of strains $2 a$ and $30 a$ were examined by the manometric method for their ability to decarboxylate the L-isomers of sixteen amino-acids. The other strains were examined for their ability to decarboxylate the L-isomers of the six amino-acids arginine, glutamic acid, histidine, lysine, ornithine and tyrosine only. The suspensions were tested at $\mathrm{pH}$ values 
of 4 and 6 . The activities for those strains in which amino-acid decarboxylases were detected are recorded in Table 3. The figures shown (expressed as $\mathbf{Q}_{\mathrm{CO}_{2}}$ ) are the higher of the two values found at the two $\mathrm{pH}$ values tested.

\section{DISCUSSION}

In the experiments recorded in this paper the optimum conditions for decarboxylase formation, and also the optimum conditions such as $\mathrm{pH}$ value and coenzyme concentration, for testing the decarboxylase activities of the washed suspensions, were not determined. The $\boldsymbol{Q}_{\mathrm{Co}_{2}}$ values recorded in Table 3 are probably considerably less than those which might have been found with specially selected conditions. Nevertheless, it is thought that the growth condition of the cells, and the conditions chosen for testing the decarboxylase activities of the washed suspensions, were such that the presence of a particular amino-acid decarboxylase would have been detected if the organism was capable of producing it in significant amounts. The media used supported heavy growth of all the strains examined, equivalent to $0.5-1.5 \mathrm{mg}$. dry wt. cell material $/ \mathrm{ml}$. culture medium. The final $\mathrm{pH}$ values of the cultures when the cells were harvested ranged from 4.0 to 5.5 with different strains, and an attempt was always made to harvest the cells towards the end of the exponential phase of growth, when their decarboxylase activities would be expected to be at their greatest (Gale, 1940a, $b, 1941$ ).

The $Q_{\mathrm{CO}_{2}}$ values found for decarboxylation of histidine by washed suspensions of the unclassified strains isolated from horse-stomach contents are greater than those recorded in other species of bacteria. Strains of coliform species had $Q_{\mathrm{CO}_{2}}$ values ranging from 1 to 33 (Gale, 1940a), and strains of species of clostridia from 3 to 60 (Gale, 1941). When grown and tested under suitable conditions, it was later found that washed suspensions of cells of strain $30 a$ could decarboxylate histidine with $Q_{\mathrm{Co}_{2}}$ values measured at $30^{\circ}$ ranging from 500 to 700 .

This small survey of the distribution of amino-acid decarboxylases in classified strains of the genus Lactobacillus indicates that these enzymes do not occur very widely in classified strains of the genus. It would seem, however, that strains which may be classified within this genus and which do decarboxylate amino-acids very actively, occur quite regularly in such environments as the stomach of the horse. If the possession of these enzymes has a survival value in a strongly acid environment, as first suggested by Hanke \& Koessler (1924), an environment such as the stomach of the horse might perhaps favour the selection of those organisms which possess active amino-acid decarboxylating systems, even among such acidophilic bacteria as the lactobacilli.

Strains $30 a$ and $6 a$ are the only strains isolated which have been studied in sufficient detail to attempt to classify them within the genus. These strains are homofermentative. They do not ferment lactose, which in Bergey's classification would relate them to $L$. delbrueckii or to $L$. leishmanii. The essential difference between these two species lies in their optimal growth temperatures, which is recorded as $45^{\circ}$ for $L$. delbrueckii and $36^{\circ}$ for $L$. leishmanii. 
The optimal growth temperature for strain $30 a$ was $c .40^{\circ}$, although the rate of growth was slightly higher at $45^{\circ}$. The carbohydrates fermented by L. delbrueckii are glucose, fructose, galactose, maltose, sucrose and dextrin, and by $L$. leishmanii, glucose, fructose, maltose, sucrose and trehalose, with slight fermentation of mannitol and $\alpha$-methyl glucoside (Bergey's Manual, 1948). Strains $30 a$ and $6 a$ fermented glucose, fructose, mannose, sucrose and trehalose. The acid produced by $L$. delbrueckii is recorded as being laevorotatory; that produced by strain $30 a$ was found to be optically inactive. Only two authentic strains of $L$. delbrueckii were examined for amino-acid decarboxylases, and none of L. leishmanii. Amino-acid decarboxylases were not found in either of the $\boldsymbol{L}$. delbrueckii strains.

The greater part of the work described in this paper was done at Cambridge, while on special study leave from the Division of Animal Health and Production of the Commonwealth Scientific and Industrial Research Organization, Australia. I wish to thank Dr E. F. Gale for his kindness in according me the facilities of the laboratory, and for his constant advice and encouragement. I am grateful to Dr M. Elisabeth Sharpe, of the National Institute for Research in Dairying, Shinfield, Reading, for supplying me with cultures of the twenty-six classified strains of lactobacilli.

\section{REFERENCES}

Årerblom, E. (1934). Über die Ätiologie und Pathogenese der Futterehe beim Pferde. Skand. Arch. Physiol. (Supplement of Band 68, Thesis).

Bergey's Manual of Determinative Bacteriology (1948). 6th ed. Ed. Breed, R. S., Murray, E. G. D. \& Hitchens, A. P. Baltimore: Williams and Wilkins Co.

EgGerth, A. H. (1939). The production of histamine in bacterial cultures. J. Bact. $37,205$.

Gale, E. F. (1940a). The production of amines by bacteria. 1. The decarboxylation of amino-acids by strains of Bacterium coli. Biochem. J. 34, 392.

GaLe, E. F. (1940 $b$ ). The production of amines by bacteria. 2. The production of tyramine by Streptococcus faecalis. Biochem. J. 34, 846.

GaLe, E. F. (1941). The production of amines by bacteria. 4. The decarboxylation of amino-acids by organisms of the groups Clostridium and Proteus. Biochem. J. $35,66$.

HaNke, M. T. \& Koessler, K. K. (1924). Studies on proteinogenous amines. XVIII. On the production of histamine, tyramine and phenol in common laboratory media by certain intestinal micro-organisms. J. biol. Chem. 59, 855.

Koessler, K. K. \& HaNke, M. T. (1919). Studies on proteinogenous amines. II. A microchemical colorimetric method for estimating imidazole derivatives. J. biol. Chem. 39, 497.

Lagerborg, V. A. \& Clapper, W. E. (1952). Amino-acid decarboxylases of lactic acid bacteria. J. Bact. 63, 393.

Proom, H. \& Worwod, A. J. (1949). The examination, by partition paper chromatography, of the nitrogen metabolism of bacteria. J. gen. Microbiol. 3, 319. 


\section{EXPLANATION OF PLATE}

Fig. 1. Lactobacillus strain $6 a$. Colony from wheat digest histidine agar shake culture after $48 \mathrm{hr}$. growth at $37^{\circ}$. (Magnification $\times 15$.)

Fig. 2. Identification of histamine in bacterial cultures by paper chromatography. Paper irrigated $2 \frac{1}{2} \mathrm{hr}$, in the organic phase of ethyl acetate + water + pyridine system. $\mathbf{R}_{f}$ histidine 0.07. $\mathrm{R}_{f}$ histamine $0 \cdot 31$. 1 , histamine $(1 \mathrm{mg} . / \mathrm{ml}$.) plus histidine $(3 \mathrm{mg} . / \mathrm{ml}$.); 2 , histidine (3 mg./ml.); 3, histamine (1 mg./ml.); 4-7, culture supernatants, strains $2 a-2 d$.

Fig. 3. Identification of histamine in bacterial cultures by paper chromatography. Paper irrigated $5 \mathrm{hr}$. in the organic phase of $n$-butanol + water + ammonia mixture. $\mathbf{R}_{f}$ histidine 0.04. $\quad \mathbf{R}_{f}$ histamine $0 \cdot 31$. I, histidine $(1 \mathrm{mg} . / \mathrm{ml}$.) plus histamine (1 mg. $/ \mathrm{ml}$.); $2-9$, culture supernatants of strains $2.1-2.8 ; 10$, histamine $(1 \mathrm{mg} . / \mathrm{ml}$.); 11 , medium control.

(Received 14 August 1952) 
Journal of General Microbiology, Vol. 8, No. 2

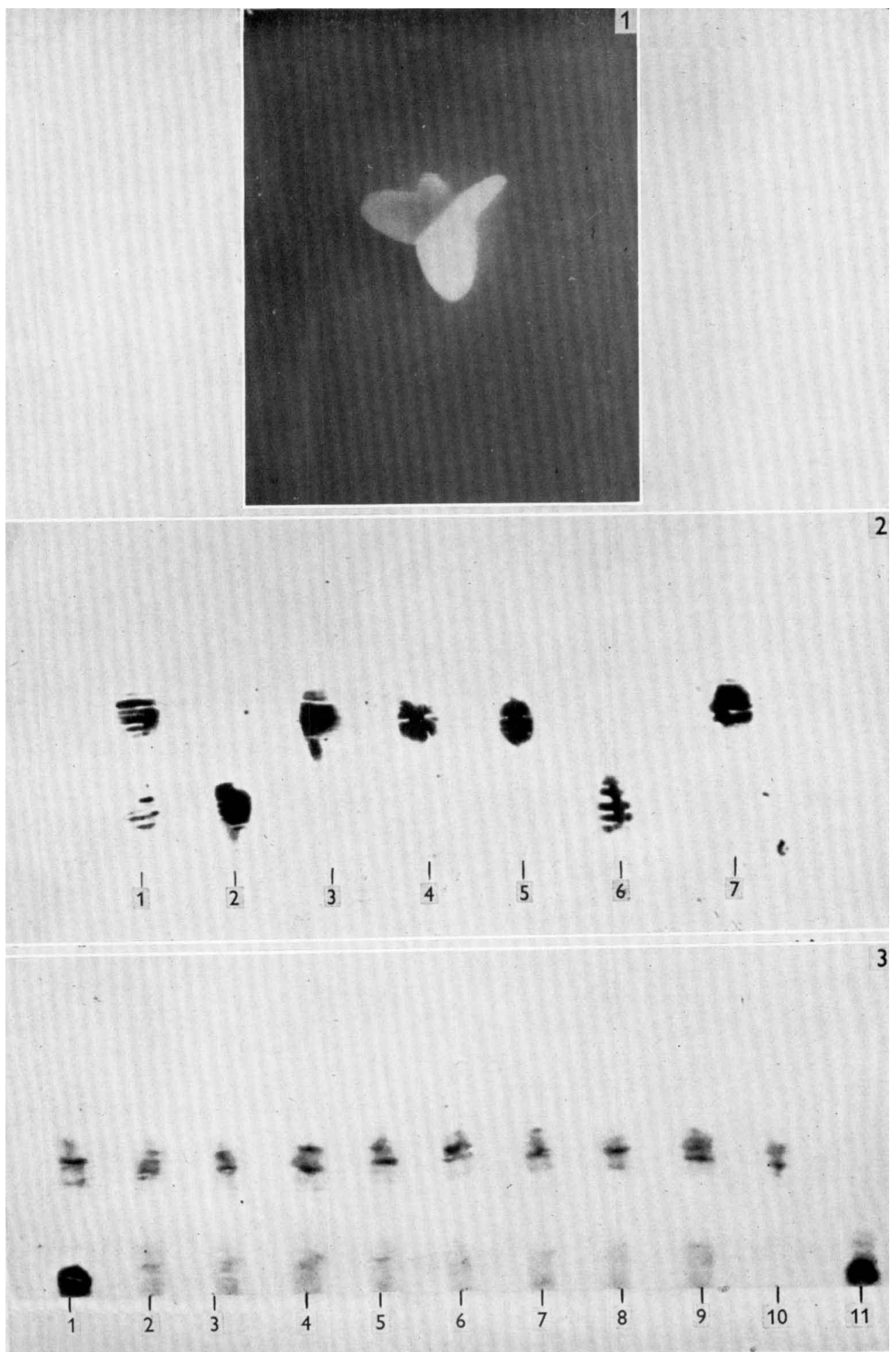

A. W. Rodweli-Amino-acid decarboxylases in Lactobacillus. Plate 1 